\title{
A CONSTRUÇĀO DA NOÇĀO DE ESPAÇO PÚBLICO: notas de leituras sobre a construção do espaço público burguês ${ }^{*}$
}

\author{
Ricardo de Jesus Silveira"-
}

\begin{abstract}
Este artigo trata da noção de espaço público construído no Estado moderno a partir do desenvolvimento da sociabilidade capitalista. Salienta o caráter heterônomo das práticas que se desenvolvem nesse espaço, determinadas pela lógica do mercado, como um desvirtuamento do caráter democrático que as pressupõem, e, de passagem, aponta para o eqüívoco da alternativa socialista que redundou no Estado totalitário. Finalmente, o artigo busca mostrar os sinais de transformação da esfera pública como resultado da falência do Estado de Bem Estar Social, fenômeno que aponta para as possibilidades de redefinição do espaço público como espaço democrático.
\end{abstract}

Palavras-chave: Espaço público; Democracia; Cidadania.

$\mathrm{M}$ uitos dos estudos atuais que buscam revalorizar a idéia de sociedade civil têm sido, de um modo geral, motivados por acontecimentos políticos que, inevitavelmente, colocaram em xeque a eficácia das formas de governo dos países do Leste, como do Estado de Bem-Estar-Social. De um lado, a falência do Estado de Bem-Estar-Social, nas suas diversas versões, revelou a incapacidade do Estado em refinanciar o desenvolvimento interno em face de sua crise fiscal, perdendo sua capacidade mobilizadora (OLIVEIRA,1988). Ademais, no Estado de bem-estar, "o recebimento passivo das benesses provindas do Estado teria minado a capacidade dos cidadãos de gerir suas próprias vidas" (COSTA, 1994, p. 39). De outro lado, a crise do socialismo real teria provocado em suas sociedades a emergência de movimentos sociais pela reivindicação de direitos civis e políticos (LEFORT,1987), nos moldes das democracias capitalistas, ensejando a revitalização da sociedade civil. O que interessaria destacar é que na idéia presente de sociedade civil, ou mais propriamente, num projeto de socie- dade civil, estaria posta a idéia, também, de seu afastamento do liberalismo, cuja integração social se faria no mercado, como também de um tipo de socialismo que viesse resultar em estatismo, como no exemplo já dado pelos países do Leste. O que cabe destacar para o propósito deste trabalho, é o fato de que associada à idéia de sociedade civil está a idéia de espaço público democrático, revitalizado pela noção de cidadania como um exercício político dos sujeitos sociais.

O espaço público a que me refiro não se restringe às instituições da democracia representativa: partidos e parlamento; nele deve haver lugar para que os movimentos sociais e demais instituições populares da sociedade civil tenham espaços de reconhecimento, representação e negociação diretamente vinculados à efetivação das políticas públicas; espaços necessários para a produção de consensos, bem como de vigilância crítica; espaços constituídos pela pluralidade dos grupos, classes e interesses correspondentes. É nessa perspectiva que as reflexões do presente artigo devem ser consideradas.

\footnotetext{
- Este texto é parte de um estudo em andamento sobre as possibilidades da constituição de um espaço público efetivamente democrático na sociedade brasileira.

“Prof.do Deptepartamento de Ciências Sociais da Universidade Eatadual de Londrina.
} 


\section{Uma aproximação à noção de espaço público burguês}

A emergência da sociedade moderna trouxe a separação entre sociedade e política - privado e público.

O Estado absolutista, teorizado por Hobbes como criação dos homens a partir do contrato social, é a construção racional que garante a paz e a liberdade "naturais", no qual os homens alienam suas vontades e submetem suas paixões.

O poder deslocado da sociedade para o Estado é pensado como um mal necessário para conter e disciplinar juridicamente uma ordem natural, que pela idéia de homens livres e iguais tornava ameaçadora a inexistência de uma racionalidade unificadora dos interesses de todos. O Estado moderno surgia, assim, como o poder capaz de impedir que uns se tornassem "lobos" de outros (HOBBES, 1979).

Não há ainda aí, uma esfera pública burguesa, até porque, não havia um mercado plenamente constituído. A esfera pública burguesa começa a se desenhar em contornos mais nítidos quando 0 mercado capitalista foge ao controle do cálculo de uma economia de troca que se desenvolvia no âmbito exclusivamente privado. Esse é um momento que coincide com a formação do Estado moderno absolutista, o qual assume o controle das mediações necessárias e demandadas pela expansão do intercâmbio de mercadorias. Por um longo tempo, tempo da existência do Estado absolutista, a esfera pública burguesa, compreendida "como a esfera de pessoas privadas reunidas em um público" (HABERMAS, 1984, p. 42), conflitará com este Estado no sentido de se ver reconhecida socialmente e ter garantida a sua representatividade política.

A teoria política liberal ganha força na medida que a esfera pública burguesa vai, paralelamente ao desenvolvimento do mercado, desenvolvendo e tornando hegemônica uma sociabilidade que lhe é própria e que tem expressão numa opinião pública, apreendida como razão superior: medida e parâmetro da ação do Estado.

O Estado liberal surge como o cristalizador do interesse geral, depois que os interesses particulares (capital, terra, trabalho), cujo lugar é a esfera privada, foram equalizados numa opinião pública (formada por cidadãos), numa reconciliação presidida pela idéia de que o mercado, "Deus", observando a "naturalidade" das relações de propriedade garante a todos a recompensa pelos seus esforços individuais de produzirem em função dos seus interesses como garantia dos interesses de todos.
A separação entre Estado e sociedade tem como mediação a esfera pública burguesa, espaço de manifestação dos cidadãos como direito assegurado juridicamente - direito positivo (prescritivo), cujo exercício garante a racionalização da política como interesse geral. Conforme Kant, citado por Habermas (1984), a mediação entre público e privado é assegurada pela publicidade, princípio que garante a comunicação entre todos, de tal forma que cada um pode dizer e ouvir o que todos ouvem e dizem, como uma condição necessária de interação para que se possam formar os juizos que correspondem às decisões que dizem respeito a todos.

Nessa medida, torna-se imprescindivel que os individuos exerçam o direito de crítica em público e com total liberdade, pois, incondicionada, a liberdade "é a pura forma dos atos que, se livres, tornam-se atos morais e ações virtuosas segundo o dever."(CHAUÍ, 1992, p. 352).

Tendo em conta a análise de Habermas do princípio da publicidade em Kant, a questão que fica é: como garantir o mesmo comportamento virtuoso dos indivíduos (cidadãos) se esse comportamento seguindo a regras do mercado faz com que uns ganhem e outros percam? Em outras palavras, como considerar que aquele que vende sua força de trabalho e aquele que compra tenham seus interesses reconciliados no Estado como interesse geral se o produto das relações de mercado não reverte para o bem comum?

A crítica hegeliana aponta para o fato de que a opinião pública não pode resultar em razão universal porque não pode superar o antagonismo dos interesses particulares no interior da sociedade sem negar a si mesma. Com efeito, a opinião pública, constituída da opinião de homens privados reunidos num público, só pode expressar uma "opinião subjetiva de muitos."

"Se o sistema antagônico das necessidades está fragmentado em interesses particulares, uma esfera pública das pessoas privadas politicamente ativas levaria a um opinar e querer inorgânico e ao mero poder de massa contra o Estado orgânico" (HABERMAS, 1984:144).

A solução hegeliana entre Estado e sociedade passa pela mediação das corporações, que teriam o papel de freio e controle das paixões - existentes como preconceitos -, e nesse sentido, a corporação desempenha função educativa, pois transforma tais interesses particulares em "bom senso", e como tal, apta a participar da política através da formulação de leis. O Estado aparece aí não como construção racional das opiniões particulares que se erigem em razão superior, mas o contrário disso, como finalidade que nega e supera as particularidades pela "universalidade do bem comum" (CHAUÍ, 1990, p. 279). 
A crítica marxista à esfera pública burguesa se apresenta como crítica radical por demonstrar, de saída, a falsidade do pressuposto sobre o qual a esfera pública se constrói: a idéia de homens livres e iguais. Não haveria liberdade nas relações sociais de produção, pois as categorias que a constituem: trabalho e capital, personificados em proletariado e burguesia, estariam, ambos, alienados ao movimento de valorização do capital. Nessas condições, a liberdade que daí resulta é uma liberdade formal: todos são livres e iguais perante a lei. Assim, o poder público que resulta da opinião pública só pode ser o poder derivado dos interesses da acumulação.

Nessa perspectiva, Marx faz tanto a crítica à teorização liberal, fundamentada em Kant através do princípio da publicidade na constituição da esfera pública, quanto à solução corporativista hegeliana, posto que esta não nega as particularidades dos interesses privados, antes, os reforça como interesses de classe.

Não obstante, é importante destacar o fato de que a constituição da esfera pública burguesa e a consolidação hegemônica da burguesia com a tomada do poder do Estado compreende um longo processo cultural de desenvolvimento da sociabilidade burguesa, que se engendrou nos espaços públicos, através das conversar e discussões entre homens privados, nos cafés, nos salões de leituras, nas festas e eventos culturais, publicizados através da imprensa, tendo, portanto, uma visibilidade pública de críticas e opiniões sobre questões sociais e políticas para além do âmbito privado da vida cotidiana; experiência que Habermas chama de constituição do "espaço público literário".

$\mathrm{O}$ destaque desse processo é importante porque nos indica a construção da hegemonia burguesa a partir da politização das questões sociais; ademais, marcou uma fase de ampliação do espaço público que passa a ter como referência a opinião pública.

Entretanto, torna-se compreensível, dada a dominação de classe da esfera pública, que uma vez construída de forma crítica e em oposição ao Estado absolutista, instituindo-se como Estado de Direito liberal - como democracia representativa -, tenha se convertido numa ambivalência entre crítica racional (idéia) e ideologia, assinalando, por conseguinte, a decadência da esfera pública como espaço político de discussão pública:

"ela penetra esferas cada vez mais extensas da sociedade e, ao mesmo tempo, perde sua função política, ou seja, submeter os fatos tornados públicos ao controle de um público crítico" (HABERMAS, 1984, p. 167).

É próprio a esse processo que a opinião pública, que antes correspondia ao exercício da razão como direito de opinião de todo cidadão, passe, progressivamente, a ser restringida pela mediação de uma sociedade que tem seus valores associados ao mercado. Num primeiro momento esse exercício é conferido àqueles cuja opinião corresponde aos valores dominantes, de forma a que tenha um sentido cívico-pedagógico. Num segundo momento, até por força do caráter de mercadoria que assume a opinião/informação, a opinião pública passa a corresponder tanto à opinião emitida pelo Estado, cuja função tem o caráter cívico-pedagógico e também normativo, como às opiniões da sociedade civil que corroboram na afirmação da opinião do Estado como a que se contrapõe criticamente aos valores e normas vigentes. (HABERMAS, 1984; CHAUÍ, 1990).

Não por acaso, ficam excluídos da esfera pública burguesa (homens privados reunidos num público que pensa politicamente) aqueles que dependem de outros para a sua sobrevivência, entre os quais, as mulheres, as crianças, e aqueles cuja única propriedade é sua força de trabalho.

É que com a "racionalização" da política, os conflitos no interior da sociedade tendem a explodir na esfera pública, potencializados que são pela ampliação dos direitos políticos. Nessa perspectiva, a dominação racional (burguesa) de conformação dos interesses na esfera pública ficaria ameaçada pela presença de uma maioria de não propritários privados de meios de produção, o que levaria a subverter a democracia, conforme a concepção liberal, por uma "ditadura da maioria" - de fato, uma real ameaça aos interesses capitalistas.

Assim, a cidadania, nos termos do liberalismo, só podia ser pautada pelo mercado. Com efeito, se os direitos civis são estendidos a todos, já no século XVIII, isso se deve às necessidades do capital que precisa de homens livres e iguais para se reproduzir. Quanto aos direitos políticos, já numa economia capitalista plenamente desenvolvida, sua ampliação ao conjunto da população só foi ocorrer no Século XX, após intensas lutas durante todo o Século XIX. O mesmo se pode dizer dos direitos sociais, cuja extensão ao conjunto da população (e ainda de forma seletiva), só se viabilizou nos mar$\cos$ do Welfare State.

Mas, isso não significa dizer, entretanto, que a constituição da esfera pública decorre de uma determinação unilateral do mercado, até porque, se assim fosse a ampliação dos direitos de cidadania jamais evoluiria do patamar logrado no final do Século XVIII. (MARSHALL, 1977).

O liberalismo, desenvolvido com intensidade durante a revolução industrial, deixou um rastro de violência e exclusão, e chegou ao seu limite com a oligopolização da economia, já na segunda metade do Século XIX, com uma esfera pública transfigurada de interesse geral em interesses de grupos e países detentores da hegemonia numa economia internacionalizada. 
Poder-se-ia dizer que a alternativa socialista, do socialismo real, como contra-hegemonia forjada no processo de construção da esfera pública burguesa, mostrou-se incompetente para garantir e aprofundar um espaço público que representasse, em síntese, um espaço de crítica e de permanente exercício democrático.

A prática política seguida em geral pelo socialismo real teria, a nosso ver, reproduzido de forma invertida a heteronomia da esfera pública construída com o surgimento da sociedade industrial capitalista. $E$ isso porque construiu artificialmente uma personalidade coletiva pela despersonalização da vida privada; uma desmercadorização das relações sociais com a construção igualmente artificial de uma imensa "sociedade comunal", ou seja, um Estado totalitário.

\section{Sinais de transformação na esfera pública}

As análise do Welfare State, segundo o modelo keynesiano do pós-45, nos mostra ter havido uma transformação significativa na esfera pública. Mas essa transformação se mostra menos pela politização das questões sociais e mais por um real processo de desmercantilização das relações sociais.

No contexto do desenvolvimento industrialtecnológico avançado, o modelo keynesiano veio a se constituir como tábua de salvação da economia capitalista:

\section{"foi o keynesianismo que forneceu os funda- mentos ideológicos e políticos para o com- promisso da democracia capitalista. Ele man- teve a expectativa de que o Estado poderia harmonizar a propriedade privada dos meios de produção com a gestão democrática da eco- nomia" (PRZEWORSKI \& WALLERSTEIN, 1988 , p. 31)}

Obedecendo a lógica da acumulação capitalista, a intervenção estatal teve um efeito duplo extraordinário, tanto no aspecto econômico como no político. Desenvolvendo políticas de pleno emprego através de investimentos em infraestrutura, tecnologia e equipamentos de consumo coletivo, atuou tanto para potenciar a acumulação, ao garantir a realização do valor dos bens socialmente produzidos, quanto para reproduzir a força de trabalho, através de salários diretos para setores organicamente mais ligados aos interesses da acumulação, como também de salários indiretos, abrangendo os setores mais amplos e menos qualificados, com relação à previdência, habitação, transportes, educação, etc.

Assim, ainda que indo ao encontro da acumulação, a reprodução da força de trabalho significa a desmercantilização das relações sociais. $\mathrm{O}$ extraordinário, no entanto, é que a desmercantilização passa a ser menos resultado da ação deliberada do Estado e mais um efeito do caráter estrutural que assume o fundo público na reprodução do capital.

Conforme Francisco de Oliveira (OLIVEIRA, 1988), a transformação provocada na esfera pública pela constituição do fundo público como necessário para viabilizar a acumulação a partir de patamares tecnológicos mais desenvolvidos significou uma "revolução copernicana". Uma mudança radical nas relações de produção, na qual o fundo público passa a funcionar não como um ex-post - resultado do processo produtivo e recurso complementar para oportunidades de investimento, com o objetivo de garantir o pleno emprego - mas, um ex-ante, um elemento estrutural fundamental à acumulação capitalista, dada a proporção que assume e a relação orgânica que o determina, tendo em vista seu caráter vital ao desenvolvimento das relações de produção.

$\mathrm{O}$ autor relata uma série de dados relativos aos países industrializados, sobre despesas sociais públicas, receitas dos governos, déficit público, dívida pública, que bem demonstram o nível de importância assumida pelo fundo público na economia capitalista. É ilustrativo, por exemplo, que o salário indireto significava, em 1981, para sete grandes países industrializados, com as exceções do Japão e dos Estados Unidos, um percentual que vai de um mínimo de $33 \%$ a um máximo de $45 \%$ em relação ao salário direto. O que revela a importância das despesas sociais públicas para viabilizar o consumo de massa.

Com relação à crise do Estado de Bem Estar Social, denunciada pelos problemas fiscais do Estado e alardeada pelo neoliberalismo com o oportunismo das palavras de ordem "privatização" ou "desestatização", atribuindo ao déficit público excessivos gastos sociais, mostra Francisco de Oliveira que a crise é "apenas e esse apenas é muito forte, a expressão da abrangência da socialização da produção, num sistema que continua tendo como pedra angular a apropriação privada dos resultados da produção social. Mas, de certo modo, ela expressa também a retração da base social de exploração..." (OLIVEIRA, 1988, p. 12).

A compreensão do problema está em que a teoria keynesiana, na qual se baseiam os Estados de Bem Estar, não responde mais ao caráter de internacionalização da economia. Ela teria funcionado se obtivesse, circunscrita à sua territorialidade nacional para financiar a reprodução do capital e da força de trabalho, retornos fiscais que permitissem realimentar o sistema. Uma vez alcançada a internacionalização produtiva e financeira em nível elevado, o que foi proporcionado pelo próprio padrão de financiamento do Estado de Bem Estar, o processo entra em crise. Crise, portanto, que deve- 
se ao fato de que "a circularidade anterior pressupunha ganhos fiscais correspondentes ao investimento e à renda que o fundo público articulova e financiava; a crescente internacionalização retirou parte dos ganhos fiscais, mas deixou aos fundos públicos nacionais a tarefa de continuar articulando e financiando a reprodução do capital e da força de trabalho" (OLIVEIRA, 1988).

O fato relevante, no entanto, é que o capital não pode prescindir dos fundos públicos, o que implica, em consequência, uma disputa pelo fundo público entre grupos e classes cujos interesses se explicitam na esfera pública. Por outro lado, o fundo público não se constituindo em valor, ainda que seja suporte da valorização do capital, ele não se reproduz enquanto valor. Com efeito, a baixa tendencial da taxa de lucro, que resulta do aumento da composição orgânica do capital, não é revertida, antes, se acentua, uma vez que a taxa de mais valia resulta, no final do processo, diminuída. E essa redução tem a ver com o fato de que parte do produto no final da relação produtiva se constitui em antimercadoria, e também volta a reiniciar o processo como antimercadoria. "A consequência teórica mais profunda é que a lei da tendência declinante da taxa de lucro se afirma pela retração da base social global de exploração..."(OLIVEIRA, 1988, p. 18).

Essa questão, a nosso ver, potencializa a esfera pública como espaço político, pois o eixo do conflito de classes tende a se deslocar para o âmbito do Estado; tal mudança, no entando, não nos parece ser suficiente para a politização das questões sociais.

O Estado, atuando como agente no processo de produção e consumo, tende a destacar-se, além das suas funções normativas, por uma lógica de mercado, na qual aparece mais como elemento que impede do que facilita a participação dos setores excluídos nos processos de discussão política. E essa tendência é tanto mais enfatizada quanto mais a esfera pública (Estado) se vê comprometida com investimentos externos. Assim, parece-me correta esta leitura se atentarmos para a realidade política brasileira, cujo modelo de desenvolvimento (e aqui, longe de pensar em Estado de Bem Estar) privilegiou sobremaneira a concentração da acumulação como bem demonstram os indicadores de concentração de renda, denunciando a esfera pública como espaço privatizado.

\section{À guisa de conclusão}

Finalizando este texto, o que aqui se buscou foi, a partir de uma rápida leitura da constituição do espaço público burguês, assinalar o seu caráter heterônomo, enquanto espaço pautado pelos interesses do mercado. Buscou-se, também, salientar os sinais de uma crise que se explicita com a falência do Estado de Bem Estar Social. Cabe, por fim, pensando a realidade brasileira, destacar uma questão que me parece sumamente pertinente, e que por se tratar de uma abordagem geral sobre o espaço público ficou à margem das considerações anteriores. Trata-se do seguinte: a marca determinante da heteronomia na existência social e política, de que fala Marilena Chauí (1990), não vem apenas da imposição de "imperativos do mercado" que reduz o espaço público, nem da "despolitização dos sujeitos sociais" transformados em objetos do Estado autoritário e tecnocrático pelo discurso da eficiência. Pertinente a essa questão é o caráter patrimonialista e prebendalista da sociedade brasileira que remonta ao período colonial. Cultura que, como destaca a mesma autora, em Conformismo e Resistência, atravessou a primeira e segunda Repúblicas e chegou até os anos 80 sem que a equivalência jurídica, própria do Estado de direito liberal fosse, de fato, reconhecida como direito de todos.

Essa é, sem dúvida, uma das questões a ser enfrentada ao se tematizar o espaço público como essencial à constituição de uma sociedade efetivamente democrática. Senão, como explicar a persistência do clientelismo nas relações de poder, do nepotismo e prebendalismo, numa confusão entre público e privado, como marcas que recusam a se afastar das práticas sociais e políticas que constituem a realidade brasileira. Esses são obstáculos que, se não superados não há como se vislumbrar um espaço público efetivamente democrático - autônomo.

\section{Referências bibliográficas}

CHAUT́, M. Cultura e Democracia. São Paulo, Brasiliense, 1990. "Público privado e despotismo". In: NOVAES, A. Ética. São Paulo, Companhia das Letras, 1992.

COSTA, S. "Esfera pública, redescoberta da sociedade civil e movimentos sociais no Brasil". Novos Estudos CEBRAP, São Paulo, n 38, 1994.

HABERMAS, J. Mudança estrutural da Esfera

Pública. Rio de Janeiro: Tempo Brasileiro, 1984

HOBBES, T. Leviatã. São Paulo, Abril Cultural, 1979. (Os Pensadores).

LEFORT, C. A invenção democrática, os limites do totalitarismo. São Paulo: Brasiliense, 1987.

MARSHALL, T.H. Cidadania, classe social e status. Rio de Janeiro, Zahar: 1967.

OLIVEIRA, F. "O surgimento do antivalor". Novos Estudos CEBRAP, São Paulo, n. 22, 1988.

PRZEWORSKI, A. \& WALLERSTEIN, M. "O capitalismo democrático na encruzilhada". Novos Estudos CEBRAP, São Paulo, n. 22, 1988 